\title{
Potentially inappropriate medication discontinued or changed based on pharmacists' recommendations in older end-stage cancer patients receiving palliative care: a cross-sectional study
}

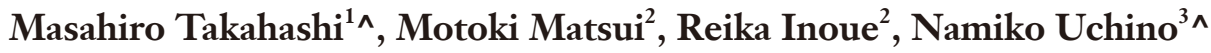 \\ ${ }^{1}$ Department of Palliative Medicine, Himeji St. Mary's Hospital, Hyogo, Japan; ${ }^{2}$ Department of Pharmacy, Himeji St. Mary's Hospital, Hyogo, Japan; \\ ${ }^{3}$ Department of Nursing, Himeji St. Mary's Hospital, Hyogo, Japan \\ Contributions: (I) Conception and design: M Takahashi; (II) Administrative support: M Takahashi, N Uchino; (III) Provision of study materials or \\ patients: M Matsui, R Inoue; (IV) Collection and assembly of data: M Matsui, R Inoue; (V) Data analysis and interpretation: M Takahashi; (VI) \\ Manuscript writing: All authors; (VII) Final approval of manuscript: All authors. \\ Correspondence to: Masahiro Takahashi, MD. Department of Palliative Medicine, Himeji St. Mary's Hospital, 650 Nibuno, Himeji-city, Hyogo 670- \\ 0801, Japan. Email: takahashi-m@himemaria.or.jp.
}

\begin{abstract}
Backgroundk Avoiding potentially inappropriate medications (PIMs) can reduce adverse events in older cancer patients receiving palliative care. However, studies have not examined the extent to which pharmacists' recommendations reduce the prescription of PIMs. Therefore, we designed a cross-sectional study to determine the extent to which their recommendations play a role in reducing the prescription of PIMs for older cancer patients receiving palliative care.

Methods: Patients brought their medications with them upon admission to the hospital. These medications were examined by pharmacists and deemed inappropriate based on the Screening Tool of Older People's Prescriptions version 2 (STOPP2). In this study, these 220 patients were surveyed, and the percentage of medications that were discontinued or changed based on pharmacists' recommendations was compared with previously published results of similar studies on older non-cancer inpatients, using univariate analysis.

Results: A total of 218 PIMs were detected in 1261 medications administered to 220 patients. Of these, 61 medications were discontinued or changed based on the recommendation of pharmacists (rate of discontinuation/change of medications: $28.0 \%$ ). The univariate analysis results showed that this rate of discontinuation or change of medications was significantly lower than that of a previous report intended for non-cancer patients $(40.6 \%)$. The rate of discontinuation/change of medications for benzodiazepines was extremely low, but for other drugs it was almost the same as in the previous report.

Conclusions: In the case of older end-stage cancer patients receiving palliative care, compared with older patients hospitalized for other diseases, it was more difficult, on pharmacists' recommendations, to discontinue or change PIMs detected by STOPP2. The low significance of discontinuing or changing benzodiazepines in subjects was a major reason it was difficult to reduce the prescription and, eventually, administer PIMs based on pharmacists' recommendations.
\end{abstract}

Keywords: End-stage cancer; potentially inappropriate medications (PIMs); Screening Tool of Older People's Prescriptions version 2 (STOPP2); benzodiazepines; older patients

Submitted Jul 01, 2021. Accepted for publication Sep 07, 2021.

doi: 10.21037/apm-21-1788

View this article at: https://dx.doi.org/10.21037/apm-21-1788

^ ORCID: Masahiro Takahashi, 0000-0002-1556-6600; Namiko Uchino, 0000-0002-8889-5763. 


\section{Introduction}

Recently, potentially inappropriate medications (PIMs) in older cancer patients have become a growing serious clinical problem, especially after Chen et al. and Mohamed et al. reported that reducing PIMs can reduce adverse events and prevent premature death in older cancer patients $(1,2)$. To reduce PIMs, it has been reported that not only physicians, who prescribe, but also pharmacists, who detect PIMs and recommend to physicians to discontinue or change the prescription, are important (3-5). Furthermore, many researchers have reported that pharmacists can reduce PIMs for older cancer patients as well, highlighting the role of these professionals in the field of cancer medicine (6-9). However, all these studies were conducted in cancer patients receiving anticancer therapy, and there have been no reports of pharmacists contributing to the reduction of PIMs in older cancer patients hospitalized in the palliative care unit. Therefore, we designed this study to investigate whether pharmacists contribute to PIMs reduction in older cancer patients hospitalized in the palliative care unit.

Criteria such as Beers Criteria, OncPal, Screening Tool of Older People's Prescriptions (STOPP), STOPP in Frail adults with limited life expectancy (STOPPFrail), among others, have been proposed to detect PIMs (10-15). The most recent version of STOPP, STOPP version 2 (STOPP2), provides more detailed criteria for determining PIMs, including the use of blood test results (16). It is also a simple and practical criterion that can be evaluated in a few minutes by trained pharmacists $(5,17)$. In our palliative care unit, we use STOPP2 among other criteria for detecting PIMs, because blood tests are basically performed upon admission. In our daily clinical practice, pharmacists detect PIMs when a patient is hospitalized in the palliative care unit and recommend to the physician to discontinue or change the prescriptions to reduce PIMs. In this study, we retrospectively reviewed the patients' medical records and evaluated the PIMs' discontinuation/change rates at our palliative care unit. Furthermore, by comparing our PIMs' discontinuation/change rates with those of a previous study, in which pharmacists reduced PIMs by intervening using the STOPP2 criterion, we investigated whether pharmacists contribute to reducing PIMs in older cancer patients hospitalized in the palliative care unit.

We present this article following the Strengthening the Reporting of Observational Studies in Epidemiology (STROBE) reporting checklist (available at https://dx.doi. org/10.21037/apm-21-1788).

\section{Methods}

\section{Study design}

This was a cross-sectional study.

\section{PIMs detection, pharmacists' recommendations and discontinuation/changes in medication}

In our palliative care unit, the following tasks have been carried out as part of our daily work since 2019. First, when a patient was admitted, the pharmacists detected the PIMs of the medications the patient was taking using STOPP2 criteria and recorded the details of PIMs in the medical record. Next, the pharmacists considered whether the detected PIMs should be discontinued, changed, or maintained. The pharmacists did not recommend the physician to discontinue or change the prescription if: (I) the detected PIMs were not very harmful medications, considering the overall condition of the patient; (II) the detected PIMs were important drugs for palliative care; and (III) the patient refused to discontinue or change the medication due to psychological or emotional problems. In all other cases, pharmacists would recommend physicians to discontinue or change the medication. Then, after receiving the recommendation from the pharmacists, the physician decided whether the recommendation was reasonable or not. If the recommendation was considered to be reasonable, the prescription was discontinued or changed. And finally, details of this process were documented in the patient's medical record on the day of admission. In this study, we accessed the medical records of these patients retrospectively and collected demographic data and descriptions of PIMs from the medical records on the day of hospitalization in this study.

\section{Sample size calculation}

To compare the PIMs' discontinued/changed rate in this study with that in the most recent previous study, in which pharmacists reduced PIMs through intervention using the STOPP2 criterion, we examined the sample size calculation. Before the main study, we conducted a preliminary study to calculate the sample size. The preliminary study was conducted on patients hospitalized in the palliative care unit from January 1 to February 28, 2021 , and the medical records at the time of admission were reviewed to investigate PIMs' discontinued/changed rate. 
The PIMs' discontinued/changed rate was $31.0 \%$. Based on the results of this preliminary study, the sample size required to compare the PIMs' discontinued/changed rate in this study with the PIMs discontinued/changed rate in the most recent previous study was 220 . The $\alpha$ risk and $\beta$ risk were set at 0.05 and 0.80 , respectively.

\section{Ethical concerns}

This study was conducted following the Declaration of Helsinki (as revised in 2013). The study was approved by the institutional ethics board of Himeji St. Mary's Hospital, Japan (No. 021-04) on April 13, 2021. The patients enrolled in the study or their legal representatives were allowed to opt out of the study and choose not to have their data used in the research from April 13 to May 31, 2020. Information on the opportunity to opt out was presented on the hospital's website. The institutional ethics board waived the requirement of informed consent.

\section{Target patients and clinical data collection}

To eliminate the possibility that the pharmacists' knowledge of the study protocol could influence their recommendations, we retrospectively enrolled 220 consecutive patients aged 65 years or older, who had been hospitalized at our palliative care unit before February 28,2021 , when the study was designed. We reviewed the medical records of these patients to collect demographic data and descriptions of PIMs.

\section{Statistical analysis}

A univariate analysis was performed to compare the PIMs' discontinued/changed rate of subjects in this study with those in the most recent previous study. All analyses were two-sided, and the statistical significance was set at 0.05 . All statistical analyses were performed with EZR (Saitama Medical Center, Jichi Medical University, Saitama, Japan), which is a graphical user interface for $\mathrm{R}$ (The R Foundation for Statistical Computing, Vienna, Austria). More precisely, it is a modified version of $\mathrm{R}$ commander designed to add statistical functions frequently used in biostatistics (18).

\section{Results}

\section{Incidence of PIMs}

All patients enrolled in this study were Japanese.
Participants' age was $79.5 \pm 7.4$ years old (mean \pm SD), and 131 were males and 89 were females. The most common type of cancer was gastric cancer, with 35 cases. This was followed by colorectal cancer with 32 cases and lung cancer with 29 cases.

One or more PIMs were found in 112 of the 220 target patients (50.9\%). Regarding the medication, 1,261 were prescribed to them, and using STOPP2, 218 were determined to be PIMs. The classification of the detected PIMs is shown in Table 1.

\section{Pharmacists' recommendations and discontinuation/ changes in medications}

The pharmacists recommended physicians to discontinue or change 65 PIMs. The physicians accepted the recommendations and discontinued/changed the prescription for 61 PIMs. Conversely, the physicians did not discontinue or change four PIMs, despite the recommendation of pharmacists. Table 2 shows the classification of the PIMs that were discontinued or changed based on pharmacists' recommendations.

The rate of discontinuation/change in medications was $28.0 \%(61 / 218)$. A univariate analysis showed that the rate of discontinuation or change in medications in our palliative unit was significantly lower than that in the most recent previous study (rate of discontinuation/change of medications: $40.6 \%$ ) (Table 2).

\section{Discussion}

The results of this study show that older cancer patients hospitalized in palliative care units have more difficulty reducing PIM detected by STOPP2 than patients admitted for other diseases. STOPP2 classifies PIMs into 13 types (16), and we detected several PIMs in Section A (Indication of medications), Section D (Central nervous system and psychotropic drugs), and Section K (Drugs that predictably increase the risk of falls in older people) in this study. The same pattern was observed in two previous studies used for comparative purposes $(3,4)$. However, the rate of discontinuation or change in medications per section seems to differ from this study. First, in Section A, 16 of 30 medications were discontinued or changed in this study (rate of discontinuation or change of medications: 53.3\%), while 11 of 22 medications were changed in the previous study (rate of discontinuation or change of medications: $50.0 \%)$. Most of the PIMs classified as Section A were 
Table 1 The classification of detected and discontinued/changed PIMs

\begin{tabular}{|c|c|c|c|}
\hline Pharmacological classes & $\begin{array}{l}\text { Number of } \\
\text { detected PIMs } \\
\text { by pharmacists }\end{array}$ & $\begin{array}{l}\text { Number of recommendations } \\
\text { for prescription discontinued } \\
\text { or changed by pharmacists }\end{array}$ & $\begin{array}{l}\text { Number of prescriptions } \\
\text { discontinued or } \\
\text { changed by physicians }\end{array}$ \\
\hline Section A: Indication of medications & 30 & 16 & 16 \\
\hline Section B: Cardiovascular system & 6 & 3 & 3 \\
\hline Section D: Central nervous system and psychotropic drugs & 38 & 4 & 4 \\
\hline Section E: Renal system & 21 & 1 & 1 \\
\hline Section F: Gastrointestinal system & 9 & 2 & 1 \\
\hline Section G: Respiratory system & 0 & 0 & 0 \\
\hline Section J: Endocrine system & 1 & 1 & 1 \\
\hline $\begin{array}{l}\text { Section K: Drugs that predictably increase the risk of falls in } \\
\text { older people }\end{array}$ & 68 & 7 & 7 \\
\hline Section L: Analgesic drugs & 23 & 23 & 23 \\
\hline Section N: Antimuscarinic/anticholinergic drug burden & 4 & 3 & 2 \\
\hline
\end{tabular}

PIMs, potentially inappropriate medications.

Table 2 Results of the univariate analysis of the rates of discontinuation/change in PIMs in our palliative care unit compared with previous report

\begin{tabular}{|c|c|c|c|c|c|}
\hline Studies & \multicolumn{2}{|c|}{ Discontinuation or change in medication } & Odd ratio & $95 \% \mathrm{Cl}$ & $P$ value \\
\hline Our study & 61 & 157 & 0.569 & $0.352-0.921$ & $0.019^{*}$ \\
\hline Previous study (4) & 54 & 79 & & & \\
\hline
\end{tabular}

*, $\mathrm{P}<0.05$ was considered significant. $95 \% \mathrm{Cl}, 95 \%$ confidence interval; PIMs, potentially inappropriate medications.

duplications of drugs, and our results showed no significant difference in the possibility of correcting duplications of drugs, even for patients with end-stage cancer. However, in Section D, 4 of 38 medications were discontinued or changed in this study (rate of discontinuation or change of medications: $10.5 \%$ ), while 25 of 64 medications were discontinued or changed in the previous study (rate of discontinuation/change of medications: $26.6 \%$ ). In Section $\mathrm{K}, 7$ of 68 medications were discontinued or changed in this study (rate of discontinuation/change of medications: $10.3 \%$ ), while 6 of 14 medications were discontinued or changed in the previous studies (rate of discontinuation/ change of medications: $42.9 \%$ ). The risk of falling was low, because the end-stage cancer patients hospitalized in the palliative care unit could not stand up. Therefore, changing or stopping the administration of PIMs of Section K, which included medications that increased the risk of falling in older patients, was unnecessary.

Furthermore, most of the drugs classified in Sections $\mathrm{D}$ and $\mathrm{K}$ were benzodiazepines. The benzodiazepines used to treat patients with end-stage delirium could not be discontinued when patients were already experiencing delirium (19). Discontinuation of regularly used benzodiazepines would generate withdrawal phenomena and cause unnecessary suffering in patients at the end of their lives (20). These reasons might have contributed to the 
lower rate of discontinuation or change of medications in this study. If we exclude PIMs classified in Sections D and $\mathrm{K}$ and compare the rates of discontinuation/change of PIMs of this study with those of previous studies, 50 of 112 PIMs were discontinued or changed in this study, while 23 of 55 PIMs were discontinued or changed in the previous studies. The rate of reductions in prescribed PIMs, in sections other than $\mathrm{D}$ and $\mathrm{K}$, was approximately the same.

However, the rate of discontinuation or change in medications for PIMs in sections other than D and K, may not differ for terminal cancer patients hospitalized in the palliative care unit, compared to other patients. This suggests that even end-stage cancer patients hospitalized in the palliative care unit, may benefit from efforts to detect and reduce the prescription of PIMs using STOPP2.

STOPP2 is a criterion that can more accurately detect PIMs using blood test results as a reference (16). Furthermore, it is so easy to use that a trained pharmacist can complete the assessment in a few minutes $(5,17)$. Therefore, we used STOPP2 to detect PIMs in our daily practice, and we used the medical records containing its results in this study. However, STOPP, an older version of STOPP2, has been shown to significantly improve medication appropriateness during hospitalization for acute illness in older patients, and its effects can be maintained for 6 months after intervention. STOPP2, like STOPP, is supposed to be applied during hospitalization for acute illness in older patients, so STOPP2 might not be optimal for end-stage cancer patients hospitalized in the palliative care unit. Better evidence might be obtained through a similar study performed using OncPal, a criterion developed to detect PIMs in cancer patients receiving end-of-life care, or STOPPFrail, a criterion developed to detect PIMs in frail patients with limited life expectancy.

Nevertheless, this cross-sectional study has some limitations. First, all the study participants were recruited from a single center; thus, they did not represent the general population of end-stage cancer patients. Second, all the participants were recruited from the patients hospitalized in the palliative care unit; thus, they did not represent the general population of end-stage cancer patients, including home patients and outpatients. Finally, neither this study, nor the previous studies used for comparison, are representative of the general population of older patients, as they were conducted on Japanese subjects. Therefore, the results must be interpreted whilst considering these limitations.

\section{Conclusions}

In the records of older patients hospitalized with endstage cancer and receiving palliative care, compared with those of older patients hospitalized for other diseases, PIMs detected by STOPP2 were more difficult to reduce based on pharmacists' recommendations. The low significance of discontinuing or changing benzodiazepines in subjects, was a major reason for the difficulty in reducing the prescription of PIMs based on pharmacists' recommendations.

\section{Acknowledgments}

We would like to thank Editage (www.editage.com) for their English language editing services. We would like to express our gratitude to Dr. Akihiro Sakashita, the chief doctor of palliative medicine of Hyogo Brain and Heart Center, who checked all the numbers regarding the detected and discontinued/changed PIMs.

Funding: None.

\section{Footnote}

Reporting Checklist: The authors have completed the STROBE reporting checklist. Available at https://dx.doi. org/10.21037/apm-21-1788

Data Sharing Statement: Available at https://dx.doi. org/10.21037/apm-21-1788

Peer Review File: Available at https://dx.doi.org/10.21037/ apm-21-1788

Conflicts of Interest: All authors have completed the ICMJE uniform disclosure form (available at https://dx.doi. org/10.21037/apm-21-1788). The authors have no conflicts of interest to declare.

Ethical Statement: The authors are accountable for all aspects of the work and ensuring that questions related to the accuracy or integrity of any part of the work are appropriately investigated and resolved. The study was conducted in accordance with the Declaration of Helsinki (as revised in 2013). The study was approved by the institutional ethics board of Himeji St. Mary's Hospital, Japan (No. 021-04) on April 13, 2021. The patients enrolled in the study, or their legal representatives were allowed to 
opt out from having their data used in the research from April 13 to May 31, 2021. Information on the opportunity to opt out was presented on the hospital website. The institutional ethics board waived the requirement of informed consent.

Open Access Statement: This is an Open Access article distributed in accordance with the Creative Commons Attribution-NonCommercial-NoDerivs 4.0 International License (CC BY-NC-ND 4.0), which permits the noncommercial replication and distribution of the article with the strict proviso that no changes or edits are made and the original work is properly cited (including links to both the formal publication through the relevant DOI and the license). See: https://creativecommons.org/licenses/by-nc-nd/4.0/.

\section{References}

1. Chen LJ, Trares K, Laetsch DC, et al. Systematic Review and Meta-Analysis on the Associations of Polypharmacy and Potentially Inappropriate Medication With Adverse Outcomes in Older Cancer Patients. J Gerontol A Biol Sci Med Sci 2021;76:1044-52.

2. Mohamed MR, Ramsdale E, Loh KP, et al. Associations of Polypharmacy and Inappropriate Medications with Adverse Outcomes in Older Adults with Cancer: A Systematic Review and Meta-Analysis. Oncologist 2020;25:e94-e108.

3. Martin P, Tamblyn R, Benedetti A, et al. Effect of a Pharmacist-Led Educational Intervention on Inappropriate Medication Prescriptions in Older Adults: The D-PRESCRIBE Randomized Clinical Trial. JAMA 2018;320:1889-98.

4. Kimura T, Ogura F, Kukita Y, et al. Efficacy of pharmacists' assessment and intervention based on Screening Tool for Older Persons' Appropriate Prescriptions for Japanese compared with Screening Tool of Older Persons' potentially inappropriate Prescriptions criteria version 2 in older patients with cardiovascular disease. Geriatr Gerontol Int 2019;19:1101-7.

5. Kimura T, Ogura F, Yamamoto K, et al. Potentially inappropriate medications in elderly Japanese patients: effects of pharmacists' assessment and intervention based on Screening Tool of Older Persons' Potentially Inappropriate Prescriptions criteria ver.2. J Clin Pharm Ther 2017;42:209-14.

6. Choukroun C, Leguelinel-Blache G, Roux-Marson C, et al. Impact of a pharmacist and geriatrician medication review on drug-related problems in older outpatients with cancer. J Geriatr Oncol 2021;12:57-63.

7. van Loveren FMAM, van Berlo-van de Laar IRF, Imholz ALT, et al. Prevalence and follow-up of potentially inappropriate medication and potentially omitted medication in older patients with cancer - The PIM POM study. J Geriatr Oncol 2021;12:80-4.

8. Whitman A, DeGregory K, Morris A, et al. Pharmacistled medication assessment and deprescribing intervention for older adults with cancer and polypharmacy: a pilot study. Support Care Cancer 2018;26:4105-13.

9. Nipp RD, Ruddy M, Fuh CX, et al. Pilot Randomized Trial of a Pharmacy Intervention for Older Adults with Cancer. Oncologist 2019;24:211-8.

10. American Geriatrics Society 2012 Beers Criteria Update Expert Panel. American Geriatrics Society updated Beers Criteria for potentially inappropriate medication use in older adults. J Am Geriatr Soc 2012;60:616-31.

11. By the 2019 American Geriatrics Society Beers Criteria ${ }^{\circledR}$ Update Expert Panel. American Geriatrics Society 2019 Updated AGS Beers Criteria® for Potentially Inappropriate Medication Use in Older Adults. J Am Geriatr Soc 2019;67:674-94.

12. Lindsay J, Dooley M, Martin J, et al. The development and evaluation of an oncological palliative care deprescribing guideline: the 'OncPal deprescribing guideline'. Support Care Cancer 2015;23:71-8.

13. Gallagher P, Ryan C, Byrne S, et al. STOPP (Screening Tool of Older Person's Prescriptions) and START (Screening Tool to Alert doctors to Right Treatment). Consensus validation. Int J Clin Pharmacol Ther 2008;46:72-83.

14. Lavan AH, Gallagher P, Parsons C, et al. STOPPFrail (Screening Tool of Older Persons Prescriptions in Frail adults with limited life expectancy): consensus validation. Age Ageing 2017;46:600-7.

15. Curtin D, Gallagher P, O'Mahony D. Deprescribing in older people approaching end-of-life: development and validation of STOPPFrail version 2. Age Ageing 2021;50:465-71.

16. O'Mahony D, O'Sullivan D, Byrne S, et al. STOPP/ START criteria for potentially inappropriate prescribing in older people: version 2. Age Ageing 2015;44:213-8.

17. Ryan C, O'Mahony D, Kennedy J, et al. Potentially inappropriate prescribing in an Irish elderly population in primary care. Br J Clin Pharmacol 2009;68:936-47.

18. Kanda Y. Investigation of the freely available easy-touse software 'EZR' for medical statistics. Bone Marrow Transplant 2013;48:452-8. 
19. Gaertner J, Eychmueller S, Leyhe T, et al. Benzodiazepines and/or neuroleptics for the treatment of delirium in palliative care?-a critical appraisal of recent randomized controlled trials. Ann Palliat Med 2019;8:504-15.

Cite this article as: Takahashi M, Matsui M, Inoue R, Uchino N. Potentially inappropriate medication discontinued or changed based on pharmacists' recommendations in older end-stage cancer patients receiving palliative care: a crosssectional study. Ann Palliat Med 2021;10(11):11301-11307. doi: 10.21037/apm-21-1788
20. Authier N, Balayssac D, Sautereau M, et al. Benzodiazepine dependence: focus on withdrawal syndrome. Ann Pharm Fr 2009;67:408-13. 